\title{
Cumpleaños en las generaciones de la Teoría Crítica de Frankfurt ${ }^{1}$
}

Mauro Basaure*

En el verano del 2009 se dio la coincidencia de que, respecto de cada una de las tres generaciones de la tradición de la Teoría Crítica de la Escuela de Frankfurt, hubo un motivo de conmemoración o celebración: en ese verano se recordó la muerte de Theodor Adorno hace cuarenta años y se celebraron dos aniversarios: el número ochenta de Jürgen Habermas y el número sesenta de su discípulo más destacado, Axel Honneth. Esta coincidencia se vio expresada en una especial cantidad de escritos en torno a esa tradición de pensamiento, en varios de los cuales la teoría crítica de Honneth fue figura protagónica.

Filosofía social y crítica (Sozialphilosophie und Kritik) se llama el libro que, en más de 700 páginas, reúne una treintena de artículos, provenientes de destacadísimos autores contemporáneos (Robert Pippin, Hans Joas, Luc Boltanski, Michael Walzer, Charles Taylor, entre otros), publicados con ocasión del sesenta aniversario de Honneth. Si este volumen conmemorativo (Festschrift) responde a la vieja tradición universitaria alemana, el libro Actualización de la crítica: Axel Honneth en conversación (Erneuerung der Kritik: Axel Honneth im Gespräch) -en el que, en un poco más de 200 páginas, son reunidas once entrevistas con Honneth, que abarcan una data de más de veinte años, y cuyo centro unificador es la perspectiva de Teoría Crítica de Honneth y su relación con la tradición de la Escuela de Frankfurt-constituye también una forma de homenaje a este importante filósofo, cuya obra, como lo muestran indirectamente estos dos escritos, se ha instalado como una de las más relevantes del debate internacional contemporáneo.

Los esfuerzos conceptuales de Honneth por renovar la tradición de la Teoría Crítica sobre la base de una teoría del reconocimiento de origen hegeliana serán puestos como el punto de partida tanto para realizar evaluaciones críticas o afirmativas, como para desarrollar intentos de prolongar la teoría honnetheana. Eso es lo que, considerado de modo global, se lee en general en Sozialphilosophie und Kritik. Efectivamente, la obra de Honneth será escrutada ahí en el marco de diversas discusiones, entre las que se cuentan aquellas sobre los fundamentos filosófico-sociales de la teoría del reconocimiento, los conceptos normativos de justicia y de autonomía, los conceptos básicos de un diagnóstico crítico de las sociedades modernas, así como aquellas sobre formas contemporáneas de teoría crítica, alternativas a la frankfurtiana.

1 Reseña de los libros: Rainer Forst, Martin Hartmann, Rahel Jaeggi y Martin Saar (eds.) (2009): Sozialphilosophie und Kritik, Suhrkamp, Frankfurt/Main; Mauro Basaure, Jean Phillip Reemtsma y Rasmus Willig (2009) (eds.): Erneuerung der Kritik. Axel Honneth im Gespräch, Campus, Frankfurt/Main, New York; Rahel Jaeggi y Tilo Wesche (eds.) (2009): Was ist Kritik?, Suhrkamp, Frankfurt/Main; Robin Celikates (2009): Kritik als soziale Praxis. Gesellschaftliche Selbstverständigung und kritische Theorie, Campus, Frankfurt/Main, New York. Reseña realizada en el marco del Proyecto Fondecyt №11100444.

* Profesor de la Escuela de Sociología, Universidad Andrés Bello. Miembro del Groupe de Sociologie Politique et Morale (GSPM), École des Hautes Études en Sciences Sociales (EHESS), París, y del Laboratorio de Teoría Social y Política (Lab_TSP), Santiago. Correo electrónico: mauro.basaure@gmail.com 
Tanto por el propio Honneth -en el libro de entrevistas Erneuerung der Kritik- como mediante la pluma de otros destacados autores -en Sozialphilosophie und Kritik- los diferentes aspectos de la crítica social que constituyen el núcleo del proyecto teórico de Honneth serán debidamente presentados y ampliamente discutidos. Ejemplo de ello es que, pese a estar ambas insertas en el marco de la teoría del reconocimiento de origen hegeliano, la crítica de la injusticia -en tanto que respuesta frente a la ausencia de reconocimiento de determinados grupos- será diferenciada ahí de la crítica de patologías sociales -en tanto que una crítica de estados sociales globales que resultan deplorables, producto de que en ellos se verían dañadas sistemáticamente las precondiciones para una vida lograda o buena-. Además de ello, una tercera forma de crítica, también dirigida contra patologías sociales, puede identificarse ahí donde se tematiza y discute el reciente intento de Honneth por actualizar el concepto luckacsiano de reificación desde una perspectiva de teoría del reconocimiento asumiendo, para ello, sin embargo, un vocabulario teórico que no siempre resulta iluminador y justificado.

Una lectura atenta permite identificar aún una cuarta forma de teoría crítica de la sociedad. Se trata, esta vez, de una crítica que cobra sus contornos ahí donde es tematizada la preocupación de Honneth por las condiciones objetivas y subjetivas que pueden ser consideradas como limitantes en el sentido de que tienden a impedir que los actores logren ejercer sus capacidades reflexivas y poner sobre el espacio público sus críticas y denuncias. Lo que esta crítica adopta como su objeto no son directamente las situaciones sociales de miseria, injusticia o patológicas, sino que las condiciones que bloquean las capacidades de los actores para que logren enjuiciar y criticar por ellos mismos dichas situaciones. Esta última forma de crítica es también el núcleo del interés de investigación de Robin Celikates, cuyo libro titulado Crítica como práctica social. Autocomprensión societaria y teoría crítica (Kritik als soziale Praxis. Gesellschaftliche Selbstverständigung und kritische Theorie), apareció recientemente junto con los mencionados arriba.

Por medio de una lectura del libro editado por Rahel Jaeggi y Tilo Wesche -que como título plantea la pregunta ¿Que es crítica? (Was ist Kritik?) y que reúne una serie de interesantes artículos que, desde muchas visiones diferentes, dan respuesta esa pregunta- es posible evaluar, de modo más o menos directo y desde perspectivas muy distintas, todas ellas contemporáneas (como, entre varias otras, aquella de Judith Butler, por ejemplo), la forma específica en que Honneth comprende la tarea de la Teoría Crítica.

Efectivamente, en Was ist Kritik?, sus diferentes visiones sobre dicha teoría serán traídas a colación una y otra vez. Así es como, en su artículo, Harmut Rosa se refiere a las experiencias de sufrimiento social de los sujetos afectados como un criterio de diagnósticos sociales críticos. Ruth Sonderegger, por su parte, trata los elementos socioontológicos del concepto de reificación de Honneth. Lo mismo puede decirse de los trabajos de Maeve Cooke, Tilo Wesche, Martin Saar y Rahel Jaeggi: todos ellos, desde diferentes perspectivas y tratando diferentes problemas, refieren a la perspectiva hegeliana de izquierda defendida por Honneth como sello distintivo de la Teoría Crítica de Frankfurt, así como al debate sobre las distintas formas de fundamentación racional de la crítica. En este sentido, Was ist Kritik? puede ser leído, en gran medida, como una forma de prolongación de Sozialphilosophie und Kritik. 
En la primera parte de Was ist Kritik?, titulada "Kritik als Praxis", Robin Celikates hace entrar en un fructífero diálogo a Honneth con el destacado sociólogo francés Luc Boltanski. La perspectiva de teoría crítica defendida por Honneth puede ser evaluada ahí -de primera mano pues se trata de la conversación entre ellos, dirigida y organizada por Celikates y que tuvo lugar en Frankfurt- desde sus encuentros y desencuentros con la sociología de la crítica desarrollada en los últimos treinta años por Boltanski como una respuesta a la sociología crítica de su maestro Pierre Bourdieu.

En el fondo, este esfuerzo de Celikates anticipaba en un par de meses un aspecto clave de su interesante trabajo doctoral, publicado bajo el título ya citado de Kritik als soziale Praxis. En este estudio, la sociología crítica de Bourdieu, la sociología de la crítica de Boltanski y la tradición de la Teoría Crítica en la que se inscribe Honneth, tienen respectivamente una relevancia sistemática. Efectivamente, de acuerdo a la reconstrucción realizada por Celikates, cada una de esas perspectivas encarna ejemplarmente un tipo o modelo específico de comprensión de la relación entre el conocimiento de la vida social que se arroga la teoría crítica de la sociedad y el conocimiento de ella de los actores ordinarios, cuestión que está en el centro del estudio metodológico de Celikates.

Honneth, quien prologa Kritik als soziale Praxis, tiene mucha razón al señalar que la discusión sobre la condición de posibilidad de la teoría crítica de la sociedad se ha concentrado, de modo unilateral, en la cuestión de la fundamentación racional de los criterios normativos sobre los que se apoyan los juicios evaluativos realizados por el teórico crítico y que el libro de Celikates, dado su mencionado interés, viene oportunamente a poner otra pregunta sobre la mesa. Para Celikates, un proyecto contemporáneo de teoría crítica de la sociedad no puede pasar por alto la exigencia fundamental, postpragmatista, de reconocer como propia una concepción de los actores sociales en tanto que capacitados cognitiva y prácticamente para el ejercicio de la crítica social. Se trata de una exigencia nacida del propio hecho de que los actores poseen efectivamente esta capacidad, de modo que la falta de un vocabulario capaz de describir "cómo se constituye la reflexividad de los actores en las prácticas sociales cotidianas y cómo ella se expresa" (p. 99) constituye un grave déficit sociológico (Verkennung der Kompetenzlogik).

En coincidencia con las críticas que Boltanski -y en parte también Honneth- le han hecho a Bourdieu, Celikates reconstruye la sociología crítica de este último de modo que ella puede ser efectivamente tomada como una forma ejemplar de una perspectiva de crítica social que peca de la fuerte tendencia a pasar por alto dicha exigencia fundamental y que, como tal, adolece de dicho déficit sociológico. Celikates habla del "modelo del quiebre" o de la discontinuidad radical entre sentido común y perspectiva científica.

Respecto de la sociología crítica de Bourdieu, la sociología de la crítica, desarrollada por Boltanski, constituye un modelo precisamente opuesto. Boltanski, dice Celikates, afirma un "modelo teórico social que metodológicamente hablando parte de las capacidades reflexivas de los actores y desde ahí configura una teoría de las prácticas de justificación y de crítica". Pero si Celikates reconoce que con el cambio paradigmático pragmatista operado por la sociología de la crítica se supera ampliamente el mencionado déficit sociológico, 
nuevamente en coincidencia con Honneth, señala que la sociología de la crítica tiende a ser ciega frente al hecho de que, por causas estructurales, las capacidades de la crítica se encuentran desigualmente distribuidas en la sociedad y que existen condiciones sociales que tienden a limitar o coartar la posibilidad de que esas capacidades -pese a su carácter innegable en cuanto tales- logren manifestarse. En la misma medida que en el modelo del cual la sociología de Boltanski es representativa (el "modelo de la simetría" entre sentido común y perspectiva científica) se tiende a ignorar estas formas de limitaciones, en esa misma medida la sociología de la crítica adolece también de un déficit sociológico (Verkennung der Blockierungslogik). Se trata esta vez, sin embargo, no de un déficit relativo al reconocimiento de las capacidades de reflexión y critica de los actores ordinarios sino que al de las condiciones subjetivas y objetivas "discapacitadoras" que impiden o bloquean la manifestación de dichas capacidades.

El propio Honneth viene aquí a prestar ayuda de Celikates: el concepto de patologías de segundo orden, al que Honneth recurre para comprender el legado de la teoría crítica, designa los déficit estructurales de reflexividad por parte de los actores (p. 168). Situaciones de primer orden -patológicas o injustas-, que los actores en principio están capacitados para identificar, juzgar, criticar y superar, no son juzgadas ni puestas en cuestión pues existen patologías de segundo orden que lo impiden. La teoría crítica contemporánea, si quiere ser verdaderamente contemporánea, debe asumir la tarea, dice Celikates, de criticar estas patologías de segundo orden, momento en el cual reconoce la lógica del bloqueo, pero todo ello sin dejar, al mismo tiempo, de reconocer la lógica de la competencia, es decir, el hecho de que "la posibilidad de la reflexión viene dada en nuestro pensamiento y nuestra acción" (p. 164).

Con mayor o menor éxito, al intento de resolver los problemas y dificultades que se generan al tratar esta espinosa cuestión se aboca Celikates, en un libro que en todo caso tendrá un lugar importante en la discusión sobre la metodología de la Teoría Crítica en los próximos años. 